\title{
Drivability Improvement Control for Vehicle Start-Up Applied to an Automated Manual Transmission
}

\author{
Danna Jiang, Ying Huang, Zhe Zuo, and Huan Li \\ Research Center of Power Machinery, Beijing Institute of Technology, Beijing 100081, China \\ Correspondence should be addressed to Zhe Zuo; zuzeus@bit.edu.cn
}

Received 22 November 2016; Accepted 21 February 2017; Published 11 May 2017

Academic Editor: Angelo Marcelo Tusset

Copyright (C) 2017 Danna Jiang et al. This is an open access article distributed under the Creative Commons Attribution License, which permits unrestricted use, distribution, and reproduction in any medium, provided the original work is properly cited.

\begin{abstract}
Drivability is the key factor for the automated manual transmission. It includes fast response to the driver's demand and the driving comfort. This paper deals with a control methodology applied to an automated manual transmission vehicle for drivability enhancement during vehicle start-up phase. Based on a piecewise model of powertrain, a multiple-model predictive controller (mMPC) is designed with the engine speed, clutch disc speed, and wheel speed as the measurable input variables and the engine torque reference and clutch friction torque reference as the controller's output variables. The model not only includes the clutch dynamic, the flexible shaft dynamic, but also includes the actuators' delay character. Considering the driver's intention, a slipping speed trajectory is generated based on the acceleration pedal dynamically. The designed control strategy is verified on a complete powertrain and longitudinal vehicle dynamic model with different driver's torque demands.
\end{abstract}

\section{Introduction}

Automated manual transmission (AMT) is widely used in modern vehicles especially in trucks due to the advantage of its low weight, low cost, and high efficiency just like a manual transmission (MT) and driving comfort without directly operating the clutch and gearshift just like an automated transmission (AT) [1]. Another transmission using a dual clutch system also has the advantage of low weight, high efficiency, and driving comport, but it is not as simple or as cost-effective as the AMT. Therefore, AMT is considered as an inexpensive add-on solution for classical MT [2].

In AMT, the start-up or gearshift phase is managed by an actuator driven clutch which is controlled by the transmission control unit (TCU) with communication to engine management system (EMS) for coordination control. It can be acceptable to the customers provided that the control strategies are able to limit the variation of the vehicle acceleration during vehicle start-up or gearshifts. That is one of the most important aspects of vehicle drivability [3]. Therefore, the drivability control in the clutch control is the key factor to guarantee the AMT performance.
Many solutions for dry clutch control in AMT have been presented in recent years. There are many different approaches proposed for dry clutch control in the literatures, for example, the classical control [4], fuzzy control [5], linearquadratic based optimal control [6-8], decoupling control [9], robust control [10], predictive control [2, 11], and the hybrid control $[6,12]$.

However, the clutch control is expected to satisfy the different and sometimes conflicting objectives, such as fast and smooth start-up. Hence, optimization based algorithm becomes a potential solution for this problem. Because the clutch dynamics in slipping and engagement phases are typical nonlinear processes, nonlinear based control methods are also needed for this problem. In this paper, we choose multiple-model predictive control strategy to design the clutch controller algorithm considering that it can handle multivariable control problem naturally and deal with nonlinear system with switching the subcontrollers. And the calculation speed is higher than hybrid predictive control strategy when the system has high order.

Unlike other researches of clutch control, this paper aims at drivability enhancement in the start-up phase of a heavyduty truck with an automated manual transmission. Not 




FIGURE 1: Overall structure of the AMT truck.

only the slipping time and jerk considered in the controller design but also the torsion vibration and actuator delays which have bad effects on the drivability of the vehicle and driver's intentions which directly affect the driver's feeling are considered as well.

The approach proposed in this paper deals with the clutch control of multiphases defined by the clutch position. In different phases, different control objectives are used. Torsion vibration which is associated with drivability and comfort is selected as one of the control objectives in every phase. In clutch going to engagement slipping phase, the other control objective is the driver's intention to decide slipping speed trajectory tracking. A hierarchical approach is used. The high level is torque reference control for engine and clutch actuator, considering the modern engine controller widely adopting torque-based method. Three angular speeds are measured as the controller inputs. They are the engine speed, clutch disk speed, and the wheel speed. The controller outputs are the optimized engine torque requirement and the clutch friction torque requirement. In this paper, we just focus on the high level of the clutch control. And the low level controller is assumed as an ideal one.

This paper is organized as follows. In Section 2, the structure of an automotive driveline is discussed, and a simplified driveline is introduced, with the dry clutch, flexible drive shaft and actuators, engine, and the clutch pneumatic actuator dynamic considered in the model. In Section 3, the different control objectives for different phase of the AMT are stated. And driver's intention is also considered in the control objectives. In this section, the control scheme based on constrained MPC strategy is presented. The switching logic is designed for different MPC controllers. In the scheme, a Kalman estimator is designed to estimate the vehicle load torque. With the estimated load torque, the prediction can be much more accurate. In Section 4 , the proposed strategy is tested and discussed. Finally, the concluding remarks are given in Section 5.

\section{System Modeling}

Figure 1 shows a rear-driven heavy-duty truck. The driveline mainly consists of the dry clutch, gearbox, propeller shaft,

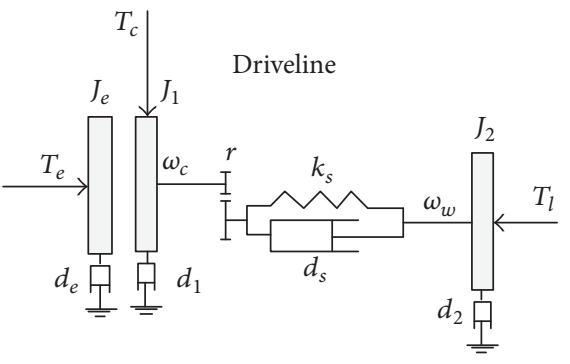

FIgURE 2: Simplified model of the driveline.

differential, half driven shafts, and wheels. The clutch electropneumatic circuit is the actuator to drive the clutch close or open. The engine is the power source which is also an actuator working together with clutch actuators.

Figure 2 shows a simplified driveline model, whereas a three-inertia model is used in this study. One inertia indicates the engine flywheel $J_{e}$ with viscous friction $d_{e}$. Another inertia indicates the equivalent mass moment from the clutch disc to the differential gear, which is summarized to $J_{1}$ with viscous friction $d_{1}$ between the clutch disc and gearbox, and the last inertia $J_{2}$ indicates the equivalent mass moment of remaining driveline and the vehicle with viscous friction $d_{2}$.

The clutch friction torque is represented by $T_{c}$ and the engine torque is represented by $T_{e}$. The gearbox ratio together with the final gear is described by the ratio $r$. It is assumed that the flexibility of drivetrain is equivalent to a spring and damper represented by $k_{s}$ and $d_{s}$. Wheel slip is neglected for simplicity. The driving resistance torque is described by $T_{l}$, which consists of the rolling resistance torque, grade resistance torque, and the aerodynamics drag torque. Usually, the resistance torques is unknown. follows

The equivalent inertia of $J_{1}$ can be calculated using (1) as

$$
J_{1}=J_{c}+J_{g 1}+\frac{J_{g 2}}{r_{g}{ }^{2}}+\frac{J_{d}}{r_{g} r_{d}^{2}},
$$

where $J_{c}$ is the inertia of clutch; $J_{g 1}$ is the inertia of the input gear of the transmission; $J_{g 2}$ is the inertia of the output gear 
of the transmission; $J_{d}$ is inertia of differential input gear; $r_{g}$ is the gear transmission ratio; and $r_{d}$ is the differential ratio. follows:

The equivalent inertia of $J_{2}$ can be calculated using (2) as

$$
J_{2}=J_{w}+m R_{w}^{2}
$$

where $J_{w}$ is the wheel inertia, $m$ is the mass of vehicle body, and $R_{w}$ is the tire radius.

The equivalent stiffness of $k_{s}$ can be calculated using (3) as follows. (The damping coefficient of $d_{s}$ is calculated by the same equation with replacing the stiffness coefficient by the damping coefficient.) The model acts as if there are several damped springs in series and parallel:

$$
\frac{1}{k_{s}}=\frac{1}{k_{c} r^{2}}+\frac{1}{k_{p} r_{d}^{2}}+\frac{1}{k_{h 1}+k_{h 2}},
$$

where $k_{c}$ is the stiffness coefficient of clutch torsion damper, $k_{p}$ is the stiffness coefficient of propeller shaft, $k_{h 1}$ is the stiffness coefficient of left half shaft, and $k_{h 2}$ is the stiffness coefficient of right half shaft

The dynamic of the drive train is decided by the clutch status. When the clutch is slipping, it is shown in

$$
\begin{aligned}
J_{e} \dot{\omega}_{e} & =T_{e}-T_{c}-d_{e} \dot{\omega}_{e} \\
J_{1} \dot{\omega}_{c} & =T_{c}-d_{1} \dot{\omega}_{c}-\frac{k_{s} \theta_{s}+d_{s} \dot{\theta}_{s}}{r} \\
J_{2} \dot{\omega}_{w} & =-T_{l}-d_{2} \dot{\omega}_{w}+k_{s} \theta_{s}+d_{s} \dot{\theta} \\
\dot{\theta}_{s} & =\frac{\dot{\theta}_{c}}{r}-\dot{\theta}_{w}=\frac{\omega_{c}}{r}-\omega_{w},
\end{aligned}
$$

where $\theta_{s}$ is the drive shaft torsion angle; $\omega_{e}$ is the engine speed; $\omega_{c}$ is the clutch speed; $\omega_{w}$ is the wheel speed.

At this time, the clutch friction torque is generated by Coulomb friction and decided mainly by the actuator force $F_{n}$, as shown in

$$
T_{c}=F_{n} \mu R_{a} \operatorname{sign}\left(\omega_{e}-\omega_{c}\right),
$$

where $F_{n}$ is the press force actuating on the clutch plate, $\mu$ is the dynamic friction coefficient of the clutch surface material, and $R_{a}$ is the effective radius of the clutch plate.

When the clutch is engaged, the engine is rigidly coupled to the driveline. At this time, the clutch slipping speed $\omega_{\mathrm{sl}}=\omega_{e}-\omega_{c}=0$. Consequently, the two equations of motion of the engine and the clutch are merged into a single equation:

$$
\left(J_{e}+J_{1}\right) \dot{\omega}_{e / c}=T_{e}-\left(d_{e}+d_{1}\right) \dot{\omega}_{e / c}-\frac{k_{s} \theta_{s}+d_{s} \dot{\theta}_{s}}{r} .
$$

Moreover, during engaged phase, the torque through the clutch cannot be altered by the actuator force anymore. Instead of a controlled input, it becomes a constrained variable.

$$
\left|T_{c}\right| \leq T_{c, \max }=F_{n} \mu_{0} R_{a},
$$

where $T_{c, \text { max }}$ is the maximum friction torque of the clutch disc and $\mu_{0}$ is the static friction coefficient.

So the switch logic model is shown in Figure 3. We define two statuses of the clutch as Slipping and Engaged.

Considering the effect of the engine and clutch actuator dynamics, the engine torque and the clutch friction torque are modeled as first-order dynamics with time delays $\tau_{e}$ and $\tau_{c}$, respectively. The equations are as follows:

$$
\begin{aligned}
& \tau_{e} \dot{T}_{e}+T_{e}=T_{e, \text { sp }}+T_{e, \text { req }} \\
& \tau_{c} \dot{T}_{c}+T_{c}=T_{c, \text { sp }},
\end{aligned}
$$

where $T_{e, s p}$ and $T_{c, s p}$ are the set points of the clutch controller for the engine controller and clutch actuator controller. And $T_{e, \text { req }}$ is the driver demand torque. The torque-based controls are now commonly used in modern engine controllers. The torque requirement from the clutch controller will be added to the driver demand torque in the engine controller. Therefore, the real engine torque is the sum of these requirements.

The engine torque delay is related to the engine speed and engine cylinder number, which is often presented by (9), where the cylinder number of the engine is $n_{\text {clinder }}$ and the engine speed is $n_{e}$ in revolutions per second.

$$
\tau_{e}=\frac{2}{n_{\text {clinder }} n_{e}} .
$$

And for the clutch actuator time delay parameter, we can use simulation result of the detailed clutch actuator model to identify it. Literature [9] has shown that the first-order linear function with the identified parameters has a similar simulation result to the detailed model.

In the continuous state-space representation, the driveline model can be written as follows (10). In the equation, the controller outputs and disturbance torque are distinguished.

$$
\begin{aligned}
& \dot{x}=A_{c} x+B_{c u} u+B_{c r} T_{e, \text { req }}+B_{c l} T_{l}= \begin{cases}A_{c 1} x+B_{c u 1} u+B_{c r} T_{e, \text { req }}+B_{c l} T_{l} & \text { (clutch status = Slipping) } \\
A_{c 2} x+B_{c u 2} u+B_{c r} T_{e, \text { req }}+B_{c l} T_{l} & \text { (clutch status = Engaged) }\end{cases} \\
& y=C_{c} x,
\end{aligned}
$$


where the state variables, input variables, and output variables are defined in as follows:

$$
\begin{aligned}
& x=\left[\begin{array}{llllll}
\omega_{e} & \theta_{s} & \omega_{c} & \omega_{w} & T_{e} & T_{c}
\end{array}\right]^{T} \\
& u=\left[\begin{array}{ll}
T_{e, s \mathrm{sp}} & T_{c, \mathrm{sp}}
\end{array}\right] \\
& y=\left[\begin{array}{lllll}
\omega_{e} & \omega_{\mathrm{sl}} & \omega_{s} & T_{e} & T_{c}
\end{array}\right] .
\end{aligned}
$$

State-space equation parameters are defined as follows:

$$
A_{c 1}=\left[\begin{array}{cccccc}
-\frac{d_{e}}{J_{e}} & 0 & 0 & 0 & \frac{1}{J_{e}} & -\frac{1}{J_{e}} \\
0 & 0 & \frac{1}{r} & -1 & 0 & 0 \\
0 & -\frac{k_{s} / r}{J_{1}} & -\frac{d_{1}+d_{s} / r^{2}}{J_{1}} & \frac{d_{s} / r}{J_{1}} & 0 & \frac{1}{J_{1}} \\
0 & \frac{k_{s}}{J_{2}} & \frac{d_{s} / r}{J_{2}} & -\frac{d_{1}+d_{s}}{J_{2}} & 0 & 0 \\
0 & 0 & 0 & 0 & \frac{1}{\tau_{e}} & 0 \\
0 & 0 & 0 & 0 & 0 & \frac{1}{\tau_{c}}
\end{array}\right]
$$

$A_{c 2}$

$$
=\left[\begin{array}{cccccc}
0 & -\frac{k_{s} / r}{J_{e}+J_{1}} & -\frac{d_{e}+d_{1}+d_{s} / r^{2}}{J_{e}+J_{1}} & \frac{d_{s} / r}{J_{e}+J_{1}} & \frac{1}{J_{e}+J_{1}} & 0 \\
0 & 0 & \frac{1}{r} & -1 & 0 & 0 \\
0 & -\frac{k_{s} / r}{J_{e}+J_{1}} & -\frac{d_{e}+d_{1}+d_{s} / r^{2}}{J_{e}+J_{1}} & \frac{d_{s} / r}{J_{e}+J_{1}} & \frac{1}{J_{e}+J_{1}} & 0 \\
0 & \frac{k_{s}}{J_{2}} & \frac{d_{s} / r}{J_{2}} & -\frac{d_{1}+d_{s}}{J_{2}} & 0 & 0 \\
0 & 0 & 0 & 0 & \frac{1}{\tau_{e}} & 0 \\
0 & 0 & 0 & 0 & 0 & 0
\end{array}\right]
$$$$
B_{c u 1}=\left[\begin{array}{cccccc}
0 & 0 & 0 & 0 & \frac{1}{\tau_{e}} & 0 \\
0 & 0 & 0 & 0 & 0 & \frac{1}{\tau_{c}}
\end{array}\right]^{T}
$$$$
B_{c u 2}=\left[\begin{array}{cccccc}
0 & 0 & 0 & 0 & \frac{1}{\tau_{e}} & 0 \\
0 & 0 & 0 & 0 & 0 & 0
\end{array}\right]^{T}
$$

$$
\begin{aligned}
& B_{c r}=\left[\begin{array}{llllll}
0 & 0 & 0 & 0 & \frac{1}{\tau_{e}} & 0
\end{array}\right]^{T} \\
& B_{c l}=\left[\begin{array}{llllll}
0 & 0 & 0 & -\frac{1}{J_{2}} & 0 & 0
\end{array}\right]^{T}
\end{aligned}
$$

\section{Controller Design}

3.1. Control Objectives. For the AMT clutch controller design, different phases need different control objectives. Usually, when vehicle is starting up, the clutch status is Slipping and Engaged in turn. Because the slipping time and the driving

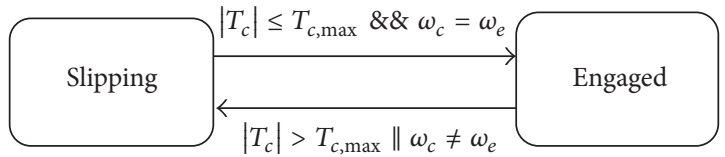

FIGURE 3: Switching logic of the clutch statuses.

comfort are conflicted, a driver intention will be used to change the slipping time dynamically. When the driver wants a faster dynamic process, the slipping time will be decreased. But when the driver does not need so fast dynamic process, then the slipping time could be increased, so as to increase the driving comfort.

Because the torsion vibration influences the driving comfort badly, the objective of torsion speed $\dot{\theta}_{s}$ should be controlled in every phase. Good drivability also means that vehicle responds to the driver's demand exactly with no delay. In this sense, the controller output should not have a big effect on the driver's intended torque. Therefore, the controller is expected to minimize the engine torque requirement from the clutch controller in clutch Engaged phase.

Moreover, the controller should satisfy the constraints such as that the engine torque and clutch torque set points should be limited in the permitted minimum and maximum values. And in order to keep the engine in the so-called nokill condition [9], the engine speed should be bigger higher than the idle speed.

For every phase, the control objective is defined as follows.

3.1.1. Slipping Phase. In Slipping phase, the conversion condition is $\omega_{\mathrm{sl}}=0$. We design a reference trajectory for clutch slipping speed as follows (13). Typical trajectory is showed in Figure 4.

$$
\begin{aligned}
\omega_{\mathrm{sl}}^{\mathrm{ref}}= & 2 \omega_{\mathrm{sl}, 0}\left(\frac{t-t_{0, \text { slipping }}}{t_{f, \text { slipping }}}\right)^{3} \\
& -3 \omega_{\mathrm{s}, 0}\left(\frac{t-t_{0, \text { slipping }}}{t_{f, \text { slipping }}}\right)^{2}+\omega_{\mathrm{sl}, 0 .}
\end{aligned}
$$

It obeys the constraint as follows:

$$
\begin{aligned}
& \omega_{\mathrm{sl}}^{\text {ref }}\left(t_{0, \text { slipping }}\right)=\omega_{\mathrm{sl}, 0}, \\
& \omega_{\mathrm{sl}}^{\text {ref }}\left(t_{f, \text { slipping }}\right)=0, \\
& \dot{\omega}_{\text {sl }}^{\text {ref }}\left(t_{0, \text { slipping }}\right)=\dot{\omega}_{\text {sl }}^{\text {ref }}\left(t_{f, \text { slipping }}\right)=0,
\end{aligned}
$$

where $\omega_{\mathrm{sl}}^{\text {ref }}$ is the reference slipping speed, $\omega_{\mathrm{sl}, 0}$ is the initial slipping speed, $t_{0, \text { slipping }}$ is the time of slipping start, and $t_{f \text {,slipping }}$ is the duration of slipping; it is a variable which is a function of driver acceleration pedal $\alpha$, shown in (15), where $t_{f, \text { slipping }}^{\mathrm{max}}$ and $t_{f, \text { slipping }}^{\mathrm{min}}$ are the maximum and minimum permitted opening time, respectively:

$$
t_{f, \text { slipping }}=t_{f, \text { slipping }}^{\max }-\left(t_{f, \text { slipping }}^{\max }-t_{f, \text { slipping }}^{\min }\right) \alpha .
$$

Meanwhile the torsion vibration should be kept small. And the engine torque should be kept close to the driver 


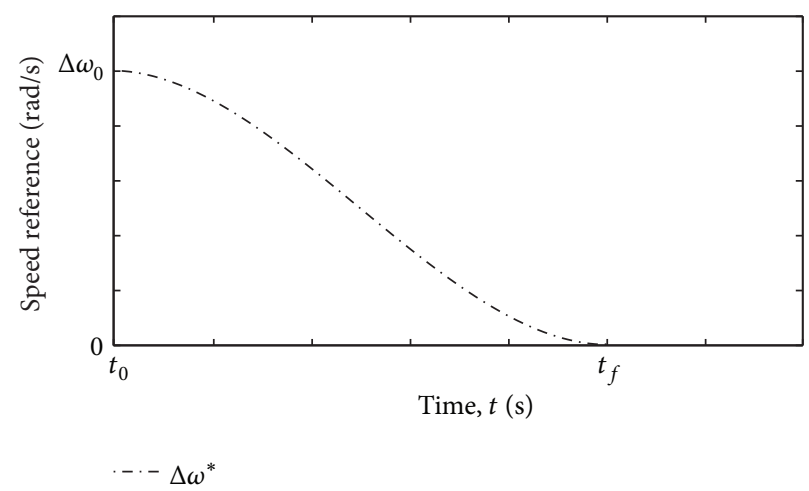

FIGURE 4: Reference trajectory of clutch slipping speed.

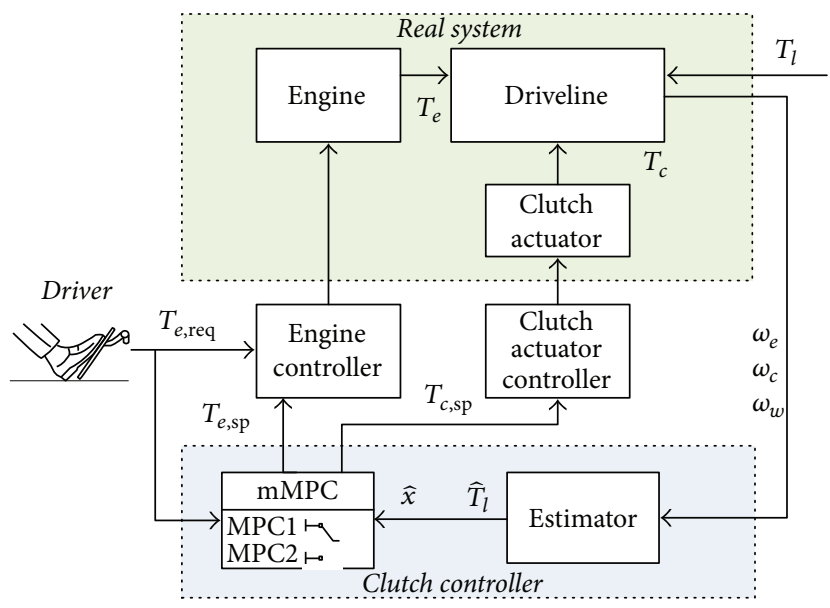

FIGURE 5: mMPC based clutch controller scheme.

torque intended. Therefore, the control objective can be written as (16). $J_{\text {slipping }}$ is the cost function of this phase.

$$
\begin{aligned}
& \min \left(J_{\text {slipping }}\right)=\min \left(\left\|\lambda_{1, \text { slipping }}\left(y_{2}-\omega_{\text {sl }}^{\text {ref }}\right)\right\|^{2}\right. \\
& \left.+\left\|\lambda_{2, \text { slipping }} y_{3}\right\|^{2}+\left\|\lambda_{3, \text { slipping }} u_{1}\right\|^{2}\right),
\end{aligned}
$$

where $\lambda_{1, \text { slipping }}, \lambda_{2, \text { slipping }}$, and $\lambda_{3, \text { slipping }}$ are weighting factors of slipping time, torsion vibration, and driver torque intended.

3.1.2. Engaged Phase. In Engaged phase, the engine is synchronized with the transmission. The clutch torque does not influence the dynamics of the driveline. But the clutch maximum static friction torque should be kept not smaller than the engine torque, so that slipping is avoided. Meanwhile, the torsion vibration should be reduced, and the engine torque should be close to the driver torque intended. So the control objective can be written as (17). $J_{\text {engaged }}$ is the cost function of this phase.

$$
\begin{aligned}
& \min \left(J_{\text {engaged }}\right) \\
& =\min \left(\left\|\lambda_{2, \text { engaged }} y_{3}\right\|^{2}+\left\|\lambda_{3, \text { engaged }} u_{1}\right\|^{2}\right) \\
& T_{c, \text { sp }}>T_{e, \text { sp }},
\end{aligned}
$$

where $\lambda_{2 \text {,engaged }}$ and $\lambda_{3 \text {,engaged }}$ are weighting factors of torsion vibration and driver torque intended.

3.2. Control Scheme. Multiple-MPC (mMPC) strategy is used for clutch control, due to the ability to handle multivariable system, to take time-domain constraints into account explicitly and deal with multiple objectives in a somehow optimal sense. What is more, there are multiphases with different control targets, so we design different controllers for different phases and switch the controllers by the clutch status.

The principle of MPC is to calculate a sequence of control actions over a finite receding horizon by optimizing the certain optimization function, while only implementing the first element on the control plant each time. In this application, the clutch control scheme is shown in Figure 5. 
An estimator uses the measured engine speed, clutch speed, and wheel speed to estimate the unmeasured disturbance $T_{l}$ and other state variables of the state-space equation in (10). Therefore, all of the state variables and disturbance input variables are measured. We can predict the future output variables of the equation. And an optimization function which is defined in Section 3.1 could be solved to calculate the target engine torque and clutch friction torque.

3.3. Load and State Variables Estimation. The vehicle is subjected to various load disturbances. Since the load mainly depends on unmeasured entities, such as slope, it is difficult to include it in the model. The literature [13] presented a method to estimate the load torque $T_{l}$. The method is based on the assumption that the load disturbance is constant or slowly varying, so it can be described or modeled as follows:

$$
\dot{T}_{l}=0 .
$$

Treating $T_{l}$ as a state variable, the system can be described as follows:

$$
\begin{aligned}
{\left[\begin{array}{c}
\dot{x} \\
\dot{T}_{l}
\end{array}\right] } & =\left[\begin{array}{cc}
A_{c} & B_{c l} \\
0 & 0
\end{array}\right]\left[\begin{array}{c}
x \\
T_{l}
\end{array}\right]+\left[\begin{array}{cc}
B_{c u} & B_{c r} \\
0 & 0
\end{array}\right]\left[\begin{array}{ll}
u & T_{e, \text { req }}
\end{array}\right] \\
& =A_{l} x_{l}+B_{l} u_{l} \\
y & =\left[\begin{array}{ll}
C_{c} & 0
\end{array}\right]\left[\begin{array}{l}
x \\
T_{l}
\end{array}\right]=C_{l} x_{l} .
\end{aligned}
$$

The state estimation is given by

$$
\widehat{\dot{x}}_{l}=A_{l} \widehat{x}_{l}+B_{l} u_{l}+K_{l}\left(y-C_{l} \widehat{x}_{l}\right) .
$$

Then $K_{l}$ is a Kalman estimator coefficient and can be calculated using the algebraic Riccati equation to minimize the estimation error.

By now, the disturbance torques $T_{e, \text { req }}$ and $T_{l}$ can be treated the same. So we define two new symbols as follows:

$$
\begin{aligned}
T_{d} & =\left[\begin{array}{ll}
T_{e, \text { req }} & T_{l}
\end{array}\right] \\
B_{c d} & =\left[\begin{array}{ll}
B_{c r} & B_{c l}
\end{array}\right]^{T} .
\end{aligned}
$$
follows:

So the state-space equation (10) can be rewritten as

$$
\dot{x}=A_{c} x+B_{c u} u+B_{c d} T_{d} .
$$

3.4. Multiple-Model Predictive Controller. Because the system state-space equation considers the engine time delay which is not a constant, the coefficients of the state equation are changed step by step. If we use method of nonlinear MPC, it will be very complex and not suitable for real-time application. Here, we introduce a new method for solving this problem. Because the delay time of the engine torque generation does not change much in a prediction horizon, we assume that the delay time is a constant in a prediction horizon. Then we can deal with the equation as a linear system

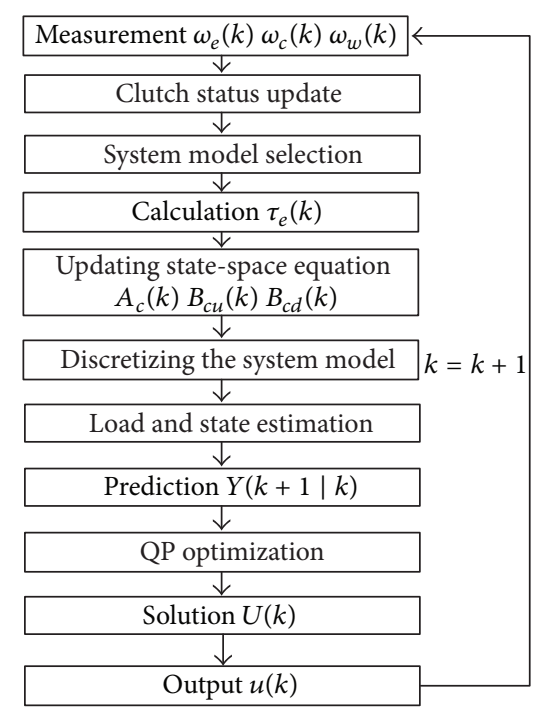

FIGURE 6: mMPC clutch controller process.

in every prediction process and keep the delay time updating step by step. So in every step, we need to firstly calculate the delay time $\tau_{e}(k)$ using the measured state $\omega_{e}(k)$ and select the right model based on the clutch status in (10). Then we update the coefficients of the state-space equation $A_{c}(k), B_{c u}(k)$, and $B_{c r}(k)$, which have relationship with $\tau_{e}(k)$. We convert the updated continuous state-space equation to discrete state-space equation using forward Euler method. Using the discrete state-space equation, we estimate the load torque $\widehat{T}_{l}(k)$ and state variables which are not measured directly based on Kalman filter strategy. After that, we can predict the output vector of the system $Y(k+1 \mid k)$ in predictive horizon. By solving the right optimization function based on the clutch status defined in Section 3.1 with constraints, the control vector in control horizon $U(k)$ can be calculated. The first element of $U(k)$ is selected to be the controller output. The whole process of the mMPC is described in Figure 6.

According to the main principle of predictive control [14], with the measured state vector $\widehat{x}(k)$ as the initial condition at time $k$, the future torsion speed is predicted on the discrete system model. In this paper, the prediction horizon is illustrated with $p$. The control horizon is illustrated with $m$, satisfying $m \leq p$. In order to reduce the system prediction equations, the assumptions are set as follows.

Out of control horizon, the control variable keeps unchanged.

Disturbance torque keeps unchanged in prediction horizon.

We define that the predicted output vector in horizon $p$ is $Y(k+1 \mid k)$ and the predicted input vector in horizon $m$ is $U(k)$ as shown in

$$
Y(k+1 \mid k)=\left[\begin{array}{c}
Y(k+1 \mid k) \\
Y(k+2 \mid k) \\
\vdots \\
y(k+p \mid k)
\end{array}\right]_{p \times 1},
$$




$$
U(k)=\left[\begin{array}{c}
u(k) \\
u(k+1) \\
\vdots \\
u(k+m-1)
\end{array}\right]_{m \times 1},
$$

where $k+1 \mid k$ represents the prediction of time $k+1$ at time $k$.

According to the basis of MPC and exploiting above contents, we can infer the sequences of outputs to be predicted and present them in the form of

$$
Y(k+1 \mid k)=S_{x} \widehat{x}(k)+S_{u} U(k)+S_{d} \widehat{T}_{d}(k),
$$

where $S_{x}, S_{d}$, and $S_{u}$ are calculated by (26) and $\widehat{T}_{d}(k)$ is calculated using the estimation variable $\widehat{T}_{l}(k)$, which is obtained from (27).

$$
\begin{aligned}
& S_{x}=\left[\begin{array}{c}
C A \\
C A^{2} \\
\vdots \\
C A^{p}
\end{array}\right]_{p \times 1} \\
& S_{d}=\left[\begin{array}{c}
C B_{d} \\
\sum_{i=1}^{2} C A_{d}{ }^{i-1} B_{d} \\
\vdots \\
\sum_{i=1}^{p} C A_{d}{ }^{i-1} B_{d}
\end{array}\right]_{p \times 1} \\
& S_{u}=\left[\begin{array}{cccc}
C B_{u} & 0 & \cdots & 0 \\
C A B_{u} & C B_{u} & \cdots & 0 \\
\vdots & \vdots & \vdots & \vdots \\
C A^{p-1} B_{u} & C A^{p-2} B_{u} & \cdots & C A^{p-m} B_{u}
\end{array}\right]_{p \times m} \\
& \widehat{T}_{d}(k)=\left[\begin{array}{ll}
T_{r}(k) & \widehat{T}_{l}(k)
\end{array}\right]^{T} .
\end{aligned}
$$

Because the main control requirement is to minimize the cost function, the optimization function can be defined as

$$
\begin{aligned}
\min _{U(k)} J(U(k), Y(k+1 \mid k)) \\
=\left\|W_{y}(Y(k+1 \mid k)-\operatorname{Re}(k+1 \mid k))\right\|^{2} \\
\quad+\left\|W_{u} U(k)\right\|^{2},
\end{aligned}
$$

where $W_{y}$ and $W_{u}$ are the weighting factor matrixes of the two objectives, respectively. $\operatorname{Re}(k+1 \mid k)$ is the reference trajectory matrix. In different phases, these two weighting factors are composed with $\lambda$ defined in Section 3.1. For the reference trajectory, because it includes time information, in every prediction step, the value can be calculated based on the time step.

The optimization problem (28) can be formulated as a quadratic programming $(\mathrm{QP})$ problem in

$$
\min _{U(k)} U(k)^{T} H U(k)-G(k+1 \mid k)^{T} U(k),
$$

where

$$
\begin{gathered}
H=S_{u}{ }^{T} W_{y}{ }^{T} W_{y} S_{u}+W_{u}{ }^{T} W_{u} \\
G(k+1 \mid k)=2 S_{u}{ }^{T} W_{y}{ }^{T} W_{y} E_{p}(k+1 \mid k) \\
E_{p}(k+1 \mid k)=\operatorname{Re}(k+1)-S_{x} x(k)-S_{d} \widehat{T}_{d}(k) .
\end{gathered}
$$

We assume that the constraints are also kept unchanged in prediction horizon. Solving the optimization function with the constraints can get the control sequence $U(k)$. Applying the first element $u(k)$ to the plant and this process is repeated at every time step.

\section{Evaluation the Controllers by Simulation}

4.1. Simulation Model. In this section, some simulation results are given and analyzed to evaluate the controllers. In order to simulate, a simulation model shown in Figure 7 is built in Matlab/Simulink/Simscape. It includes the longitudinal vehicle dynamics, lumped mass driveline, mean value engine model, pneumatic clutch actuator, and the engine controller and clutch actuator controller model. . The constructed simulation model can capture the important transient dynamics of the driveline, such as the delay of the engine torque generation, the delay of the clutch actuator, clutch damper vibration, flexible drive shaft, and half drive shaft oscillation. As well as tire slip, even road slope and road surface which may have an effect on the clutch controller are all included in the model. Some main vehicle parameters are listed in Table 1.

For the engine model, the input is fuel mass and, for the clutch actuator, the input is solenoid On/Off valves; an engine controller and clutch actuator controller are also modeled with simplified control strategy. And we assume that these two controllers have high control accuracy. In order to simulate the gearshift, a simple gear controller is modeled. It just includes gearshift timing. And the clutch control strategy described in this paper is also built as a model in Simulink. In this simulation, the sampling period for MPC control updating is set to $10 \mathrm{~ms}$, and the simulation updating period is $1 \mathrm{~ms}$.

4.2. Simulation Results. In order to fully evaluate the controllers, there are several maneuvers defined as follows:

(1) Open loop control for the start-up with low torque demand (M1)

(2) Open loop control for the start-up with high torque demand (M2)

(3) Close loop control for the start-up with low torque demand (M3) 


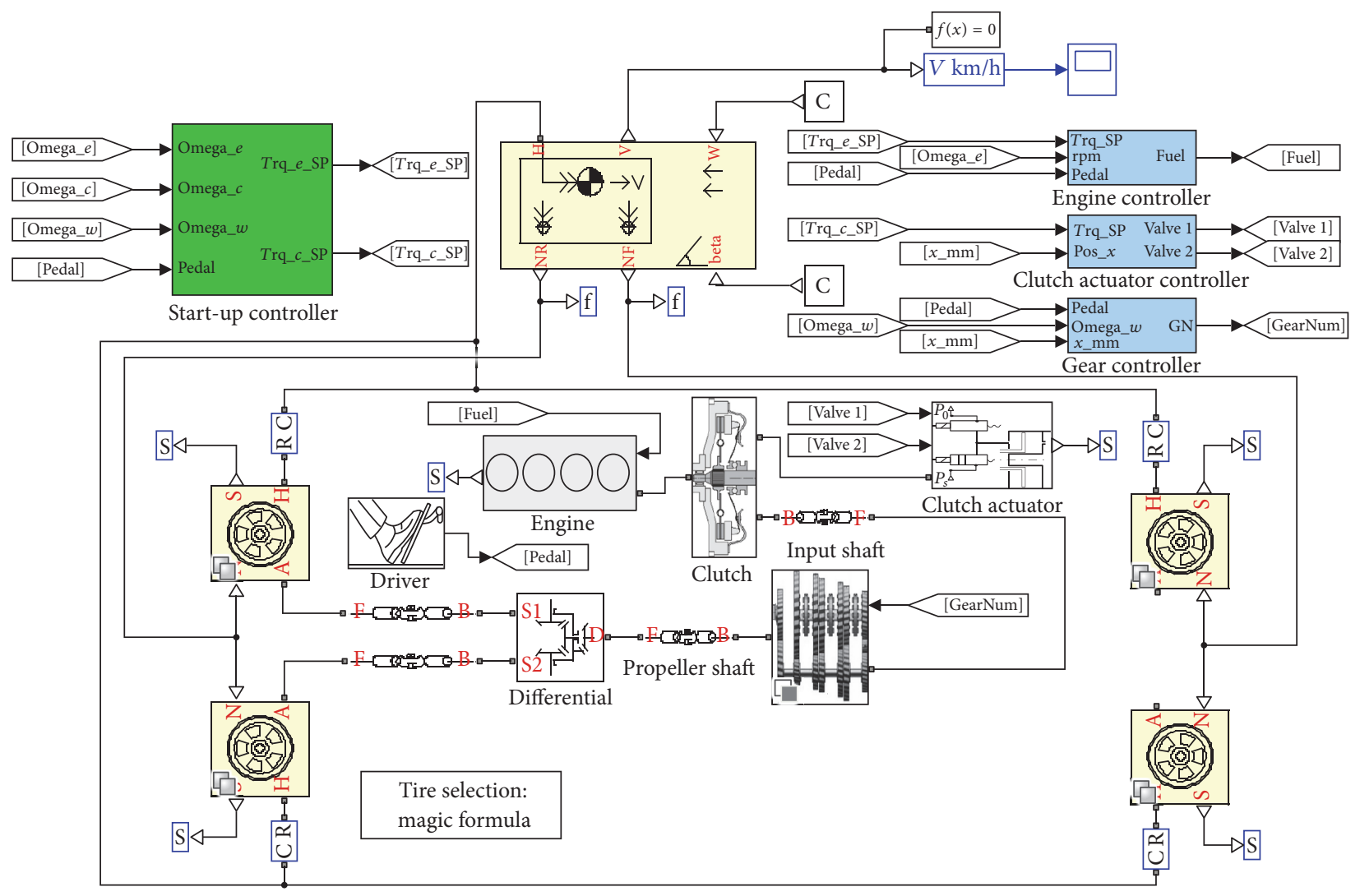

FIGURE 7: Simulation model of a heavy-duty truck.

TABLE 1: Normal values of parameters of simulation model.

\begin{tabular}{|c|c|c|}
\hline Symbol & Parameters & Value \& unit \\
\hline$J_{e}$ & Engine flywheel inertia & $2.1 \mathrm{~kg} / \mathrm{m}^{2}$ \\
\hline$J_{c}$ & Clutch disk inertia & $0.1 \mathrm{~kg} / \mathrm{m}^{2}$ \\
\hline$J_{g 1}$ & $\begin{array}{c}\text { Equivalent inertia of gearbox primary } \\
\text { shaft }\end{array}$ & $0.1 \mathrm{~kg} / \mathrm{m}^{2}$ \\
\hline$J_{g 2}$ & $\begin{array}{c}\text { Equivalent inertia of gearbox secondary } \\
\text { shaft }\end{array}$ & $0.1 \mathrm{~kg} / \mathrm{m}^{2}$ \\
\hline$J_{d}$ & $\begin{array}{l}\text { Equivalent inertia of propeller shaft and } \\
\text { differential gear inertia }\end{array}$ & $0.1 \mathrm{~kg} / \mathrm{m}^{2}$ \\
\hline$J_{2}$ & $\begin{array}{l}\text { Equivalent inertia of half drive shaft and } \\
\text { wheels and vehicle }\end{array}$ & $4020 \mathrm{~kg} / \mathrm{m}^{2}$ \\
\hline$d_{e}$ & Damping of engine shaft to bearings & $0.1 \mathrm{Nm} / \mathrm{rad} / \mathrm{s}$ \\
\hline$d_{c}$ & Damping of clutch shaft to bearings & $0.1 \mathrm{Nm} / \mathrm{rad} / \mathrm{s}$ \\
\hline$d_{2}$ & Damping of wheels to bearings & $2 \mathrm{Nm} / \mathrm{rad} / \mathrm{s}$ \\
\hline$d_{s}$ & Damping of the drive shaft & $3 \mathrm{kNm} / \mathrm{rad} / \mathrm{s}$ \\
\hline$k_{s}$ & Stiffness of the drive shaft & $175 \mathrm{kNm} / \mathrm{rad}$ \\
\hline$r$ & Transmission ratio of drive train & 35.04 \\
\hline$n$ & Engine cylinder number & 6 \\
\hline$\tau_{c}$ & Clutch actuator delay time & $0.3 \mathrm{~s}$ \\
\hline$m$ & Vehicle mass & 16 ton \\
\hline$R_{w}$ & Radius of tire & $0.5 \mathrm{~m}$ \\
\hline
\end{tabular}

(4) Close loop control for the start-up with high torque demand (M4)

Figures 8 and 9 are the simulation results of maneuvers M1 and M2. M1 and M2 are maneuvers without clutch optimization controller. M1 starts with a low driver demand engine torque which is $100 \mathrm{Nm}$. And clutch friction torque is also set to $100 \mathrm{Nm}$. M2 starts with a high driver demand engine torque which is $800 \mathrm{Nm}$. And clutch friction torque is also set to $800 \mathrm{Nm}$. From the simulation results, we can see that, for both M1 and M2, there are torsion vibrations in both Slipping and Engaged phase. And the vibration frequency in Slipping phase is higher than that in Engaged phase. Higher torque can evoke serious oscillation but can shorten the slipping time. From Figures 8(c) and 9(c), we can see that the acceleration curves also show many shakes and jerks in the whole process. The shake and jerk evoke a bad drivability.

Figure 10 is the simulation results of maneuver M3. M3 is the start-up maneuver with optimization controller with low driver torque demand which is $100 \mathrm{Nm}$. It is a low driver pedal position input. Therefore, the controller generates a reference slipping speed trajectory as shown in Figure 10(d) lasted about $5 \mathrm{~s}$. From the simulation results in Figures 10(a)-10(d), we can see that the torsion vibration is reduced and the engine speed tends to increase at a nearly fixed rate. The acceleration of the whole process does not have many shakes 


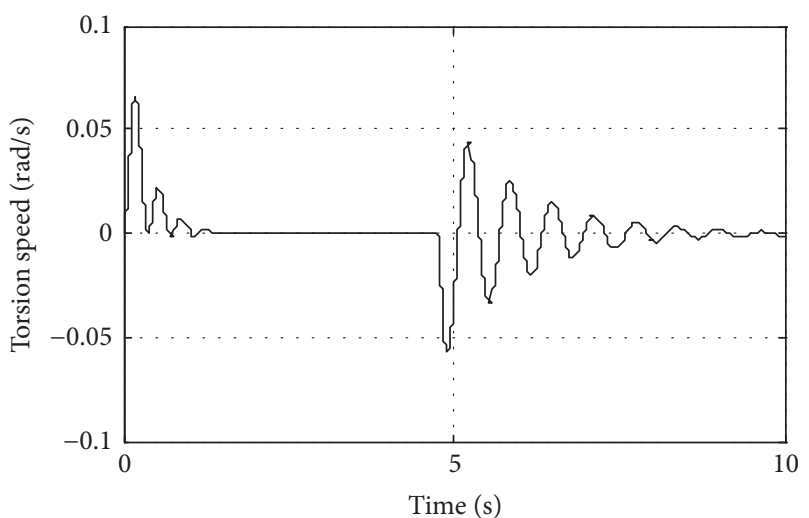

(a)



(b)

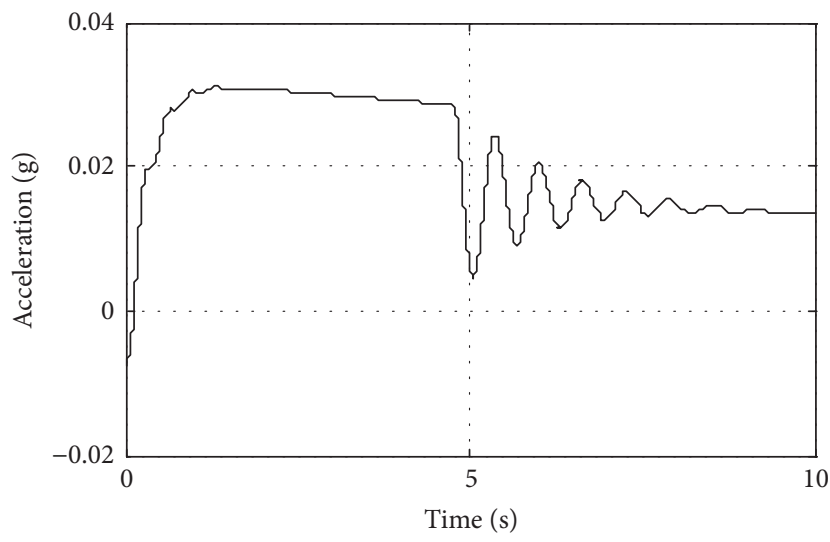

(c)

FIGURE 8: M1 maneuver simulation results.

and jerks, and the slipping speed has a good tracking to the reference trajectory. From Figures 10(e)-10(f), we can see that the controller outputs are in the area of constraints. We set the constraint of engine torque requirement from clutch control as $[-100 \mathrm{Nm}, 200 \mathrm{Nm}]$. The minimum value is based on that the engine real torque cannot be lower than zero. The maximum value is based on the low driver pedal maximum engine torque limit. We set the constraint of the

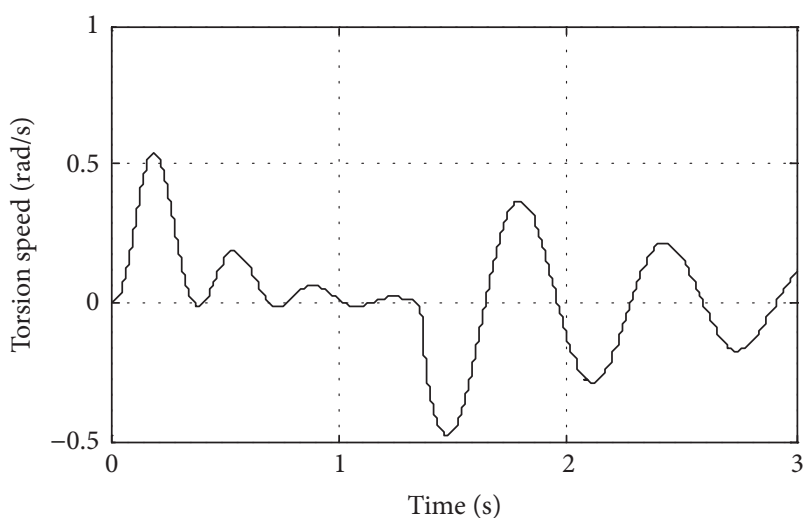

(a)

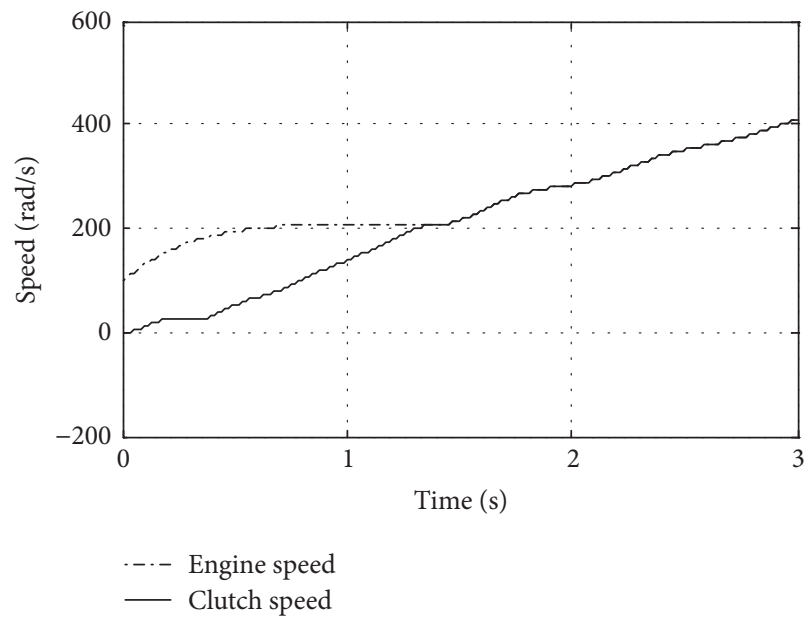

(b)



(c)

FIGURE 9: M2 maneuver simulation results.

clutch friction torque as $[0,300 \mathrm{Nm}]$, with considering that the clutch torque should not be larger or lower than engine torque.

Figure 11 shows the simulation results of maneuver M4. M4 is the start-up maneuver with optimization controller with high driver torque demand which is $800 \mathrm{Nm}$. It is a high driver pedal position input. So the controller generates a reference slipping speed trajectory as shown in Figure 11(d) 


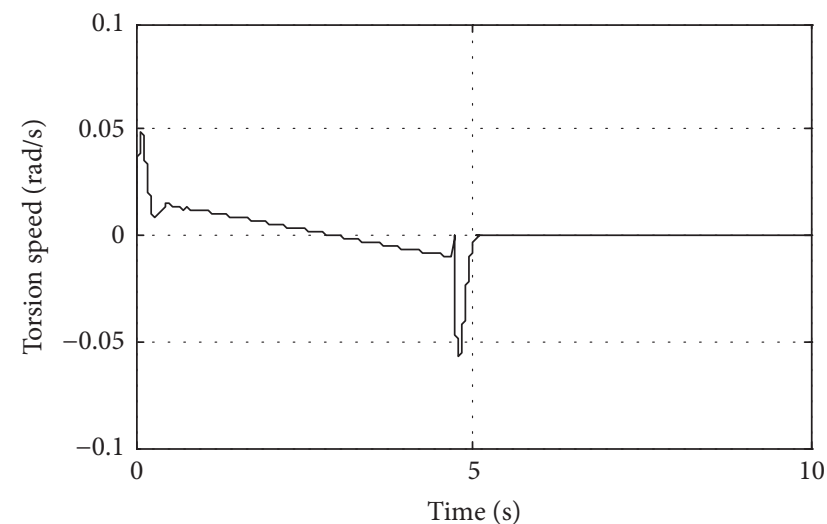

(a)

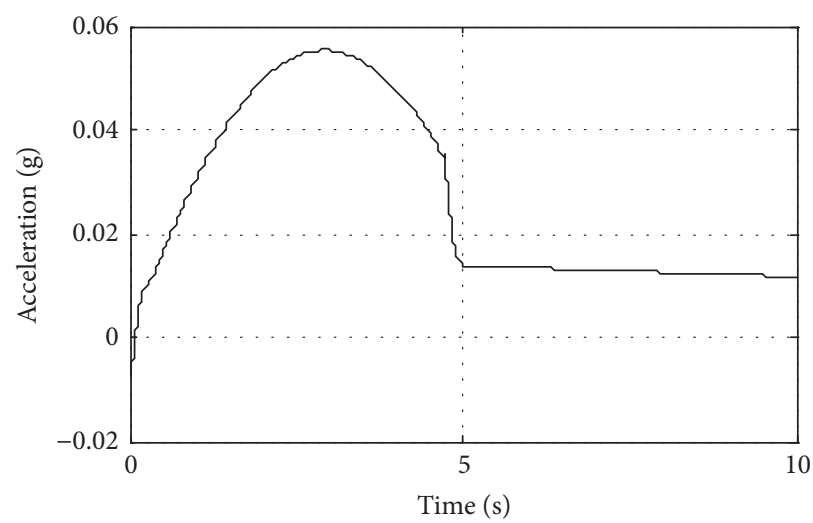

(c)

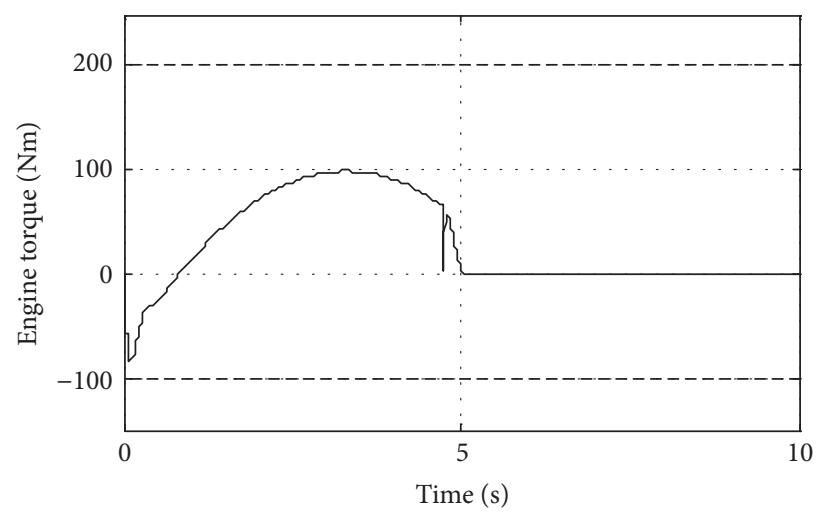

(e)

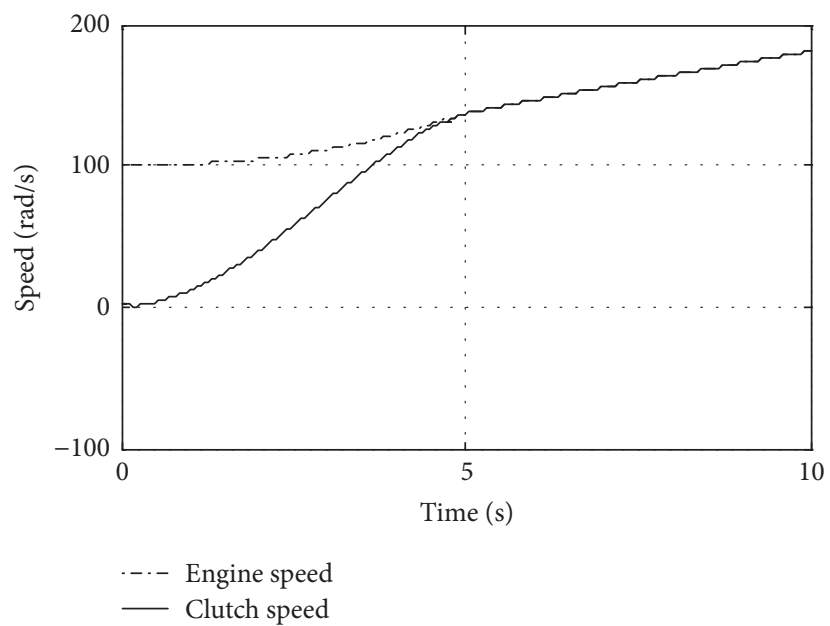

(b)



-.- Reference

- Simulation

(d)

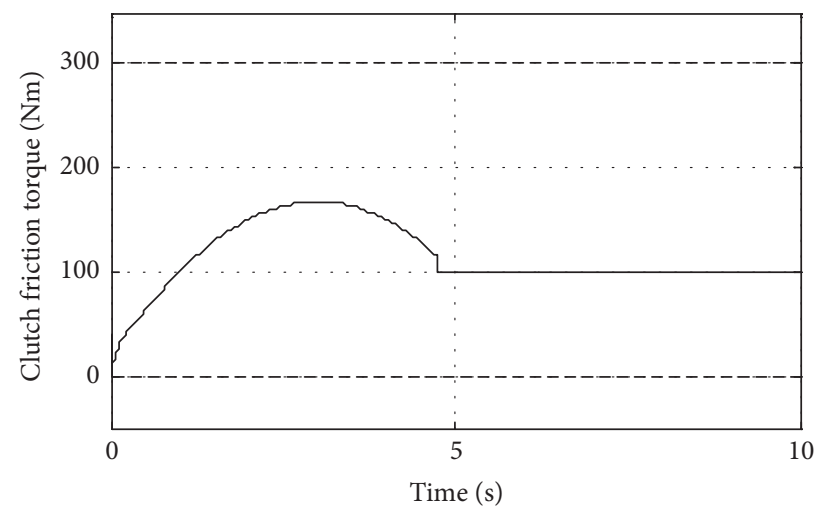

(f)

FIGURE 10: M3 maneuver simulation results.

lasted about $1.5 \mathrm{~s}$. From the simulation results in Figures 11(a)-11(d), we can see that the torsion vibration is reduced and the engine speed tends to increase at nearly fixed rate. The acceleration of the whole process does not have many shakes and jerks, and the slipping speed has a good tracking to the reference trajectory. From Figures 11(e)-11(f), we can see the controller outputs are in the area of constraints. We set the constraint of engine torque requirement from clutch control to $[-800 \mathrm{Nm}, 300 \mathrm{Nm}]$. The minimum value is based on that the engine real torque cannot be lower than zero. The maximum value is based on the high driver pedal maximum engine torque limit. We set the constraint of the 

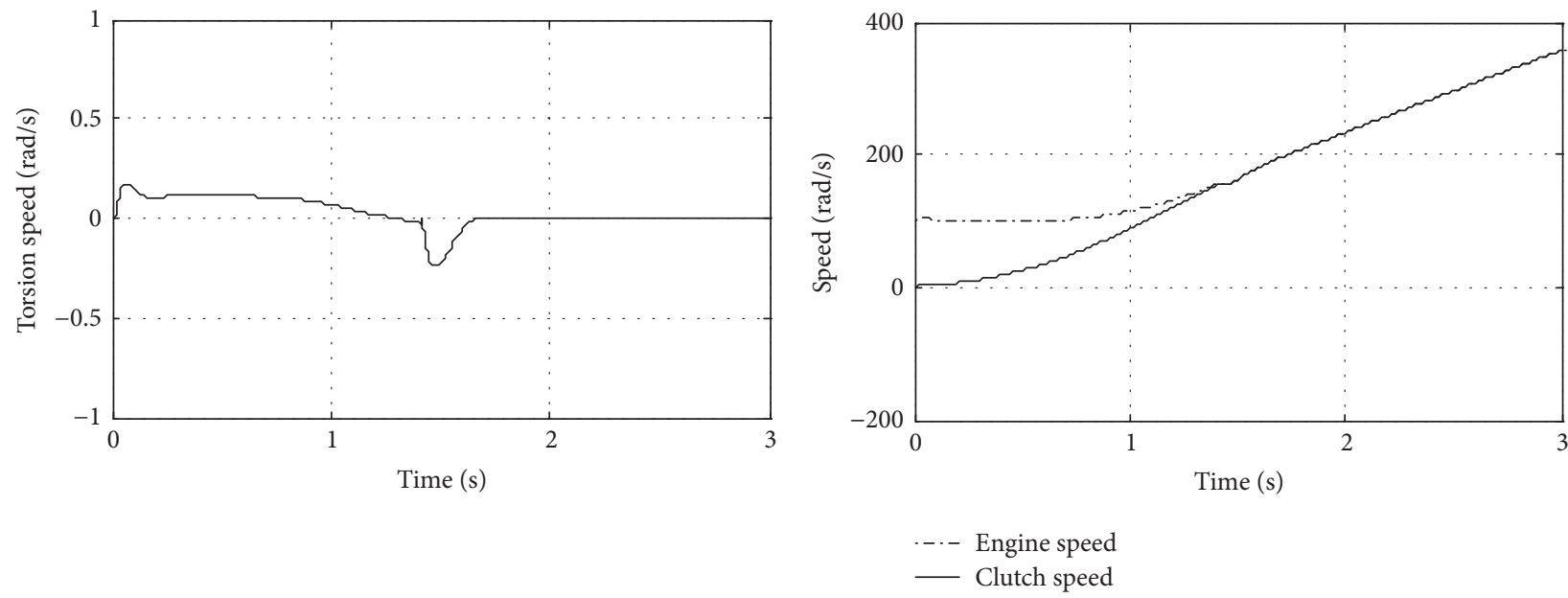

(a)
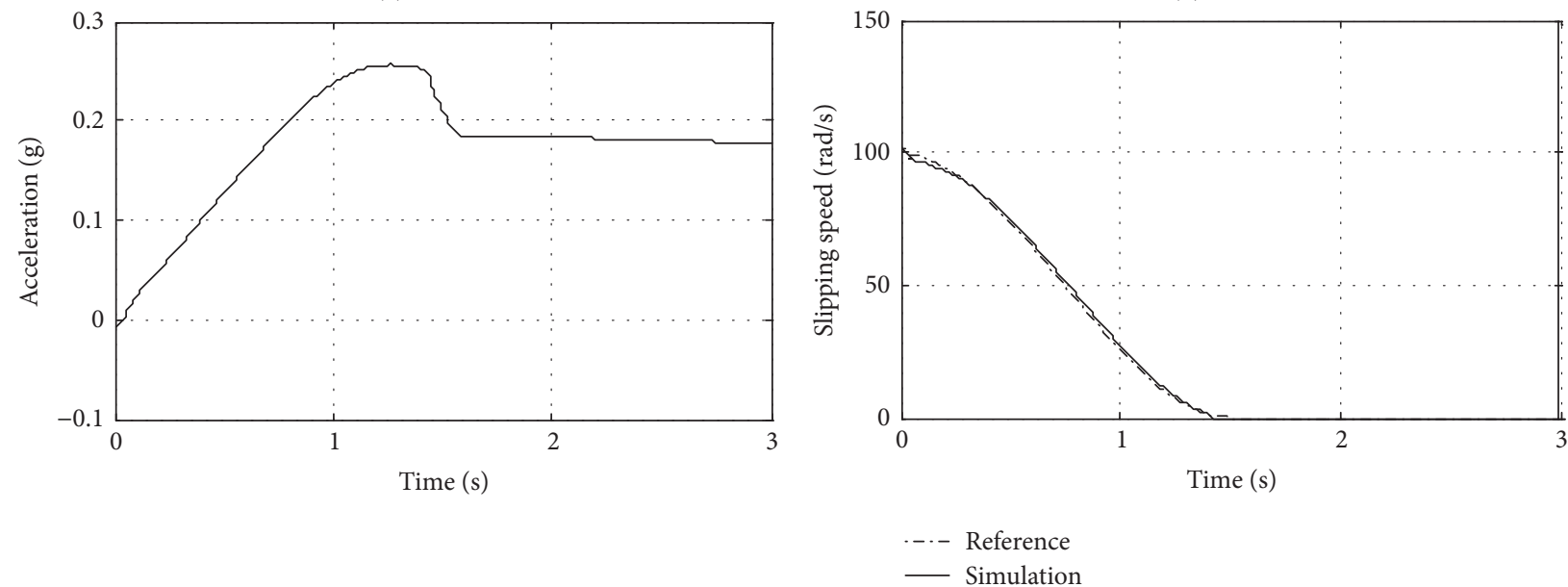

(c)
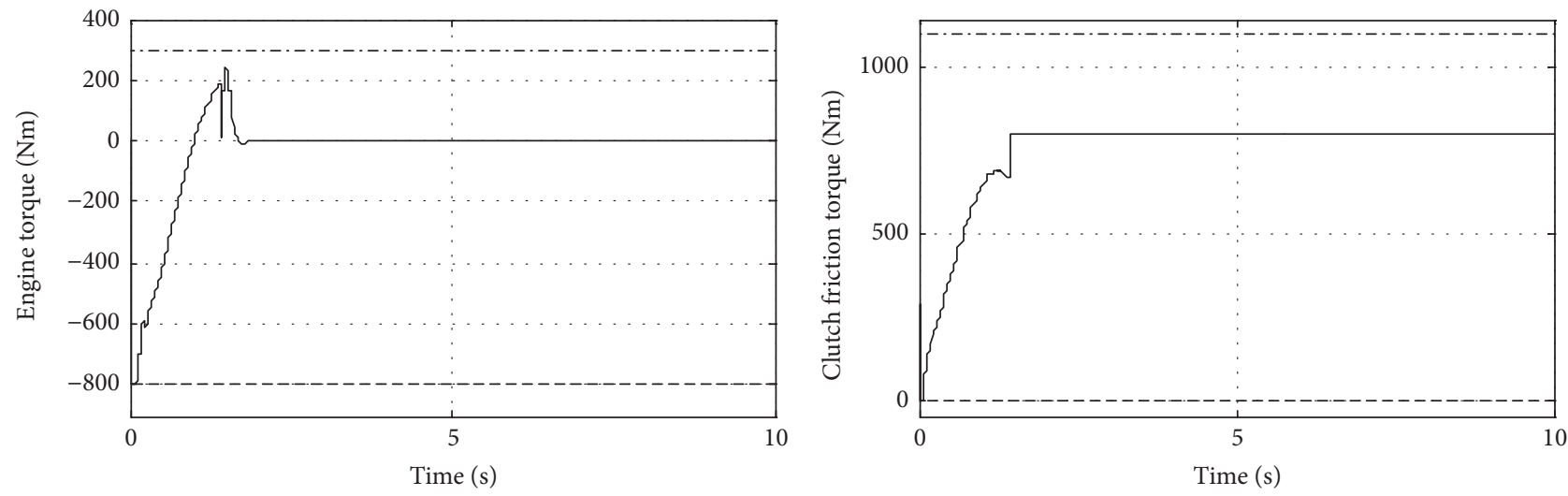

(e)

(f)

FIGURE 11: M4 maneuver simulation results.

clutch friction torque to $[0,1100 \mathrm{Nm}]$, with considering that the clutch torque should not be larger or lower than the engine torque.

\section{Conclusions}

A multiple-MPC for dry clutch control for AMT truck has been proposed. Two driveline models are built based on the clutch position. Two different control objectives are designed for different phases including Slipping and Engaged phases. Therefore, two MPC controllers with two prediction models are designed for the AMT clutch control for the start-up process. In these controllers, the clutch slipping time is decided by the driver's intention. The torsion vibration is controlled not only in the Engaged phase but also in the Slipping phase. Simulation results have shown the mMPC 
controllers have good performance in each phase during start-up process in AMT truck. The drivability of the vehicle is enhanced with the optimization controller.

The proposed scheme is only for the start-up process control so far, it will be enhanced in the future for the gearshift process control to form a complete high level controller for the AMT clutch control.

\section{Conflicts of Interest}

The authors declare that there are no conflicts of interest regarding the publication of this paper.

\section{Acknowledgments}

The authors would like to acknowledge the National Natural Science Foundation of China for financially supporting this research under Project no. 51475043.

\section{References}

[1] G. Lucente, M. Montanari, and C. Rossi, "Modelling of an automated manual transmission system," Mechatronics, vol. 17, no. 2-3, pp. 73-91, 2007.

[2] R. Amari, M. Alamir, and P. Tona, "Unified MPC strategy for idle speed control, vehicle start-up and gearing applied to an automated manual transmission," in Proceeding of the 17th IFAC World Congress, Seoul, South Korea, 2008.

[3] R. E. Dorey and C. B. Holmes, "Vehicle driveability-Its characterisation and measurement," SAE Technical Papers, 1999.

[4] R. Zanasi, A. Visconti, G. Sandoni, and R. Morselli, "Dynamic modeling and control of a car transmission system," in Proceeding of the IEEE/ASME International Conference on Advanced Intelligent Mechatronics, Como, Italy, 2001.

[5] V. T. Minh and A. A. Rashid, "Automatic control of clutches and simulations for parallel hybrid vehicles," International Journal of Automotive Technology, vol. 13, no. 4, pp. 645-651, 2012.

[6] A. C. Van der Heijden, A. F. Serrarens, M. K. Camlibel, and H. Nijmeijer, "Hybrid optimal control of dry clutch engagement," International Journal of Control, vol. 80, no. 11, pp. 1717-1728, 2007.

[7] P. Dolcini, H. Béchart, and C. C. De Wit, "Observer-based optimal control of dry clutch engagement," in Proceedins of the 44th IEEE Conference on Decision and Control, and the European Control Conference, (CDC-ECC '05), pp. 440-445, Prague, Czech, December 2005.

[8] P. Dolcini, C. Canudas de Wit, and H. Béchart, "Lurch avoidance strategy and its implementation in AMT vehicles," Mechatronics, vol. 18, no. 5-6, pp. 289-300, 2008.

[9] L. Glielmo, L. Iannelli, V. Vacca, and F. Vasca, "Gearshift control for automated manual transmissions," IEEE/ASME Transactions on Mechatronics, vol. 11, no. 1, pp. 17-26, 2006.

[10] G. J. L. Naus, M. A. Beenakkers, R. G. M. Huisman, M. J. G. Van De Molengraft, and M. Steinbuch, "Robust control of a clutch system to prevent judder-induced driveline oscillations," vol. 48, pp. 1379-1394, Proceedings of the 8th International Symposium on Advanced Vehicle Control, Kobe, Japan.

[11] M. Pisaturo, M. Cirrincione, and A. Senatore, "Multiple constrained MPC design for automotive dry clutch engagement," IEEE/ASME Transactions on Mechatronics, vol. 20, no. 1, pp. 469-480, 2015.
[12] A. Bemporad, F. Borrelli, L. Glielmo, and F. Vasca, "Hybrid control of dry clutch engagement," in Proceeding of the 6th European Control Conference, (ECC '01), Porto, Portugal, 2001.

[13] J. Fredriksson, H. Weiefors, and B. Egardt, "Powertrain control for active damping of driveline oscillations," Vehicle System Dynamics, vol. 37, no. 5, pp. 359-376, 2010.

[14] D. Q. Mayne, J. B. Rawlings, C. V. Rao, and P. O. Scokaert, "Constrained model predictive control: stability and optimality," Automatica, vol. 36, no. 6, pp. 789-814, 2000. 


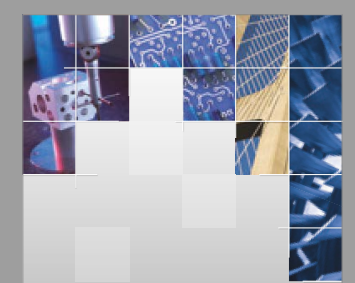

\section{Enfincering}
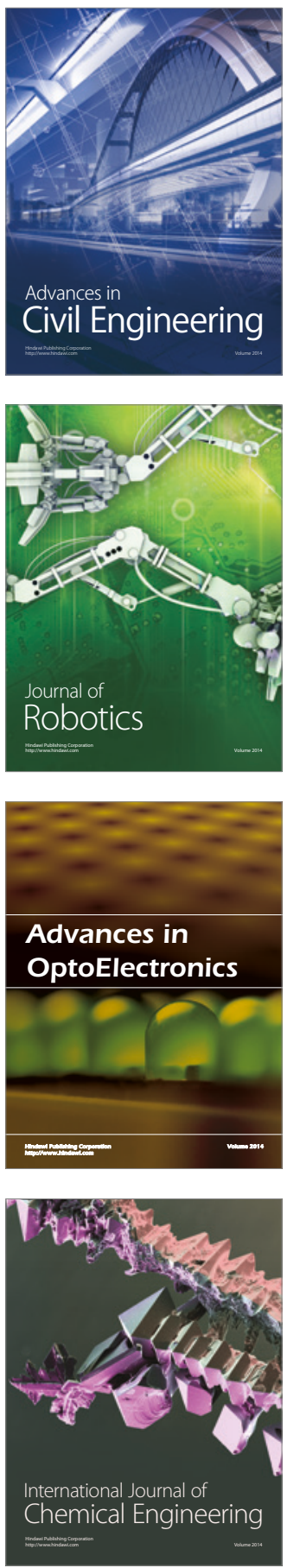

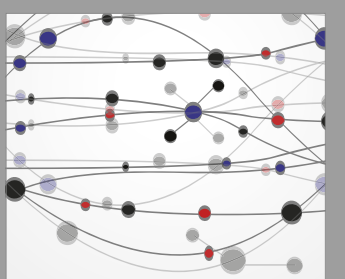

The Scientific World Journal

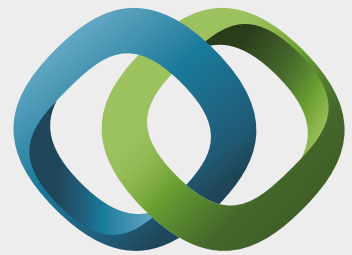

\section{Hindawi}

Submit your manuscripts at

https://www.hindawi.com
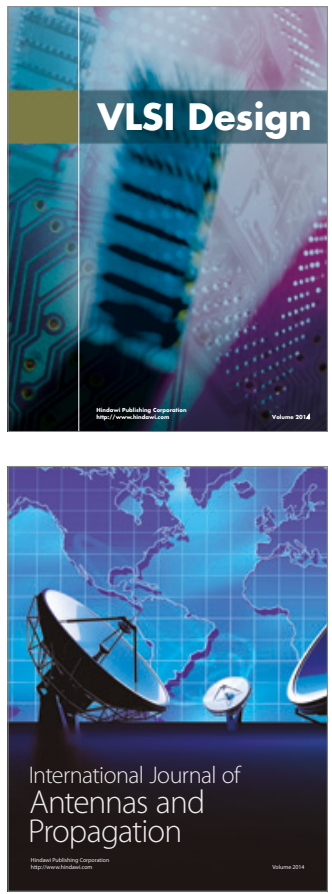

\section{Rotating}

Machinery
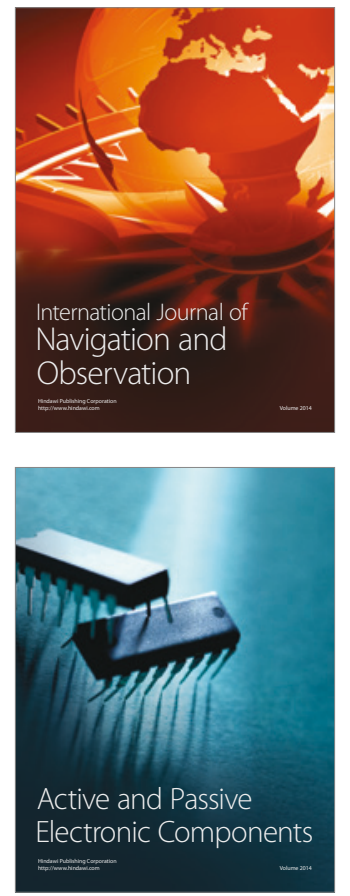
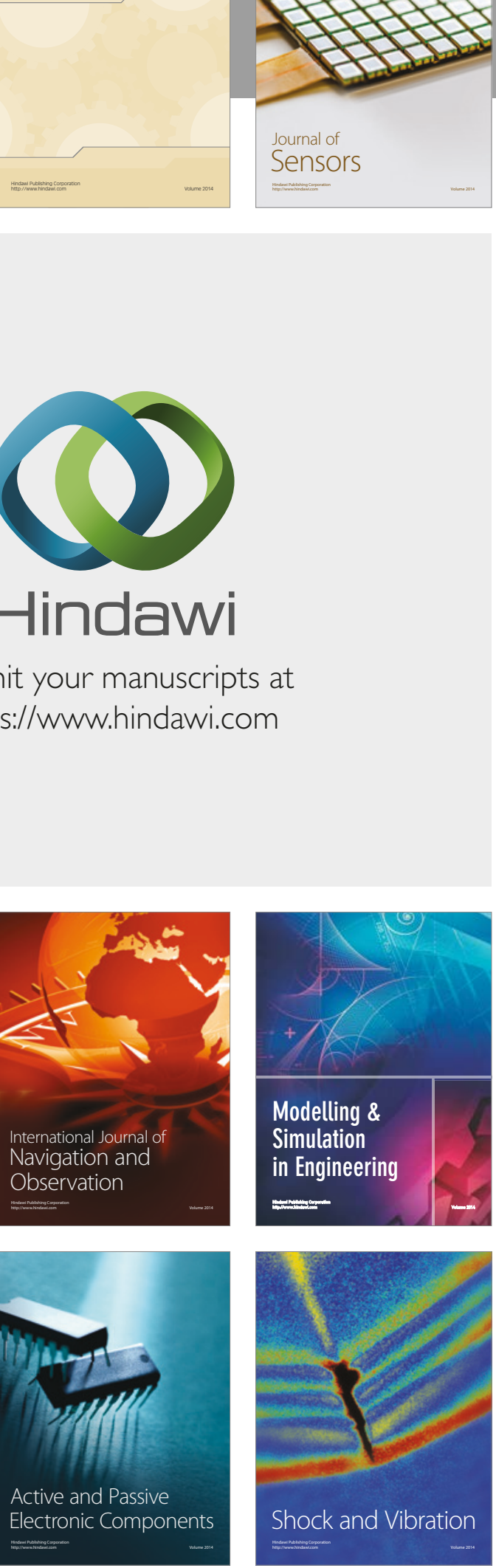
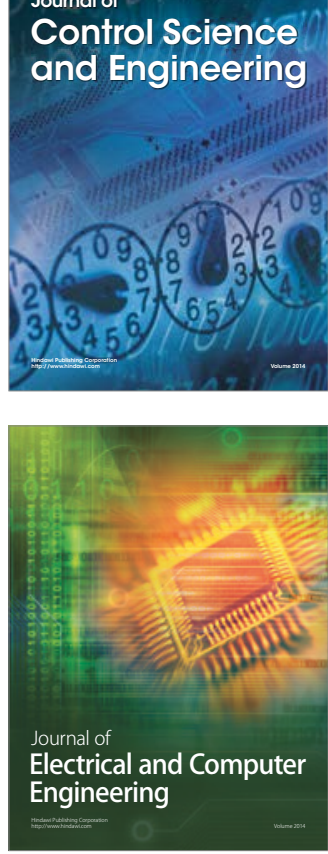

Distributed

Journal of

Control Science

and Engineering
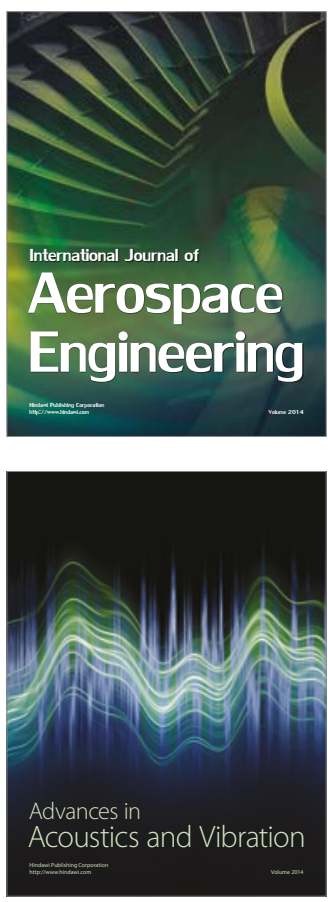

Sensor Networks 